\title{
Role of Dead Sea Climatotherapy in the Treatment of Psoriasis Vulgaris
}

\author{
${\text { Nooshin Bagherani }{ }^{*} \text {, Bruce R. Smoller }{ }^{2} \text {, Arieh Ingber }}^{3}$ \\ 'Dermatologist at Dr. Nooshin Bagheran's office, Taha Physicians' building, Khoramshahr, Khuzestan Province, Iran \\ ${ }^{2}$ Department of Pathology and Dermatology, University of Rochester, School of Medicine and Dentistry, USA \\ ${ }^{3}$ Department of Dermatology, Hadassah Hospital, Hebrew University, Jerusalem, Israel
}

"Corresponding author: Dr. Nooshin Bagheran's, Dermatologist, Taha Physicians' building, P.O. Box: 6414715878, Khoramshahr, Khuzestan Province, Iran; E-mail: nooshinbagherani@yahoo.com

Citation: Bagherani, N., et al. Role of Dead Sea Climatotherapy in the Treatment of Psoriasis Vulgaris. (2016) Invest Dermatol Venereol Res 2(2): 78-78.

\author{
Received date: September 8, 2016 \\ Accepted date: September 9, 2016 \\ Published date: September 12, 2016
}

Psoriasis vulgaris is a common skin disorder whose therapeutic regimens are mostly based on immunity-targeted agents and modalities ${ }^{[1]}$. Phototherapy remains a mainstay in treating moderate to severe forms of psoriasis.

For more than 40 years, the efficacy of Dead Sea Climatotherapy (DSC) has been known in the treatment of psoriasis. In this method, daily exposures to the sun, which is strictly medically controlled, induces an intense modulation of the immune system. With this modality, exposure to ultraviolet B is low.

In a study, Harary et al. assessed the role of DSC in treating psoriatic patients who were referred to the Deutsches Medizinisches Zentrum (DMZ) during the past five years. In this retrospective cohort work, 790 subjects were studied through evaluating the Psoriasis Area Severity Index (PASI) score. The authors confirmed the efficacy of DSC in treating psoriasis vulgaris. Besides this main finding, this study also revealed the following results:

Previous treatments with the DSC asa positive predictor for achieving better PASI $\%$.

A positive association between the length of the disease and PASI $\%$.

A negative association between age at onset of disease and PASI $\%$.

Fitzpatrick's skin type II as a positive predictor for improving PASI \%.

Additionally, no significant association was found between PASI \% and age, gender, site of involvement, body mass index, and duration of therapy, PASI score at arrival and dose of sun exposure.

The authors conclude that DSC is an invaluable option for the treatment of patients with moderate to severe psoriasis.

\section{Reference}

1. Harari, M., Sela, Y., Ingber, A., et al. Dead sea climatotherapy for psoriasis vulgaris: analysis of short-term results. (2016) Glob Dermatol 3(3): 295-301.

Online ISSN: 2381-0858

Journal Title: Investigative Dermatology and Venereology Research Journal Short Name: Invest Dermatol Venereol Res
Ommega Online Publishers

E-mail: editor.dermatology@ommegaonline.org

Website: www.ommegaonline.org 
